\title{
Desenvolvimento preliminar de gel de lapachol: estudo de permeação in vitro
}

\author{
Ana Amélia Moreira Lira', Elizângela de Araújo Sester', Luiz Renato Pires Abreu', \\ Leila Bastos Leal da Silva ${ }^{1}$, Almir Gonçalves Wanderley, Davi Pereira de Santana ${ }^{1, *}$
}

${ }^{1}$ NUDFAC-Núcleo de Desenvolvimento Farmacêutico e Cosmético. Departamento de Ciências Farmacêuticas. Universidade Federal de Pernambuco

- Correspondência:

D.P. Santana

NUDFAC - Núcleo de

Desenvolvimento Farmacêutico e

Cosméticos

Departamento de Ciências

Farmacêuticas

Universidade Federal de Pernambuco

Av. Prof. Arthur de Sá, s/n - Cidade

Universitária

50740-520 - Recife - PE

E-mail: d-santana@bol.com.br
O objetivo do presente estudo foi desenvolver formulações geleificadas do lapachol, substância de conhecida atividade antiinflamatória. Para otimização das formulações, foi verificada a influência da resina de Carbopol ${ }^{\circledR}$ empregada (934P, 940 e 941), do $\mathrm{pH}$ da formulação (5, 7 e 8), da concentração do princípio ativo $(0,2 \%, 0,5 \%$ e 1,0\%) bem como da incorporação de um promotor de absorção (Polissorbato 80) na liberação in vitro do lapachol utilizando células de difusão tipo Franz. Para tanto foram usadas como barreiras membrana sintética Durapore ${ }^{\circledR}$ e pele de rato albino tipo Wistar. Os resultados demonstraram que a adição do Polissorbato 80 na formulação promoveu aumento significativo na permeação do princípio ativo através da pele estudada, exceto para os géis contendo 0,2\% de lapachol utilizando Carbopol $l^{\circledR} 934 P$ como agente geleificante. Estes géis apresentaram as melhores taxas difusionais de lapachol, principalmente quando incorporados em formulações com pH 8, nas concentrações de 0,5\% ou 1,0\% de princípio ativo. Todavia as preparações contendo 1,0\% de princípio ativo apresentaram pequenos cristais de lapachol não solubilizados.
Unitermos

- Lapachol

- Géis

- Difusão in vitro

\section{INTRODUÇÃO}

A administração tópica é conhecida como via alternativa da administração oral de ativos medicamentosos e oferece muitas vantagens como a ausência de efeito de primeira passagem (Guy, 1985; Gwak et al., 2002 ). A habilidade de um fármaco presente em formulações tópicas em permear a pele depende da sua capacidade de liberação do veículo para a pele, e da difusão por esta barreira para seu sítio de ação. São poucos os compostos de interesse terapêutico que possuem propriedades físico-quími- cas adequadas para penetrar rapidamente a epiderme viável e principalmente o estrato córneo constituído por células ricas em queratina envolvidas em múltiplas camadas lipídicas que representam a principal barreira a permeação (Yokomizo, 1996; Shokri et al., 2001). Assim, vários artifícios têm sido empregados objetivando reduzir a propriedade de barreira da pele e promover a penetração transdérmica do fármaco (Chien, 1992).

Muitos fármacos encontram-se na forma de eletrólitos fortes a moderadamente fracos de modo a proporcionarem equilíbrio de espécies ionizadas e não- 
ionizadas. Estas espécies afetam diretamente a penetração sendo a forma não-ionizada a que possui melhor permeabilidade, embora estudos têm demonstrado que o aumento na solubilização do fármaco através da sua ionização pode proporcionar aumento da penetração e do fluxo do fármaco (Zatz, 1983; Swarbrick et al., 1984, Aunst et al., 1990; Gwak et al., 2002 ). Uma estratégia para aumentar a permeabilidade de determinados fármacos é a incorporação de promotores de absorção na formulação (Barry, 1983; Moser et al., 2001). Neste sentido, tem sido demonstrado que estes compostos podem alterar reversivelmente a composição e/ou organização lipídica e protéica inter e intracelular do estrato córneo, proporcionando difusão adequada do fármaco através da pele (Santus et al., 1993; Yamane et al., 1995).

O lapachol [2-hidróxido-3-(3-metil-2-butenil)-1,4] é uma naftoquinona, que possui atividade antiviral, antimicrobiana, antiinflamatória e principalmente anticancerígena. Nos estudos clínicos descritos na literatura seja utilizando pacientes portadores de cervicites e cérvico-vaginites crônicas (Wanick et al.,1970), seja utilizando pacientes portadores de bursite, otite, tendinite e sinusite (Correia et al., 1988), a atividade antiiflamatória do fármaco foi comprovada.

Neste mesmo contexto, estudo preliminar de desenvolvimento galênico e difusão in vitro do lapachol incorporado em formas farmacêuticas geleificadas realizado por Santos et al. (1991) mostrou a viabilidade da incorporação desse composto em formas tópicas.

Assim, com base nos relatos anteriores e considerando a via cutânea como alternativa e muitas vezes como complemento de outras vias de administração, o objetivo deste trabalho consiste no desenvolvimento preliminar do lapachol na forma gel utilizando ensaios de permeação in vitro, mediante a análise de aspectos como a influência da resina de Carbopol ${ }^{\circledR}$ empregada (934P, 940 e 941), do pH $(5,7$ e 8$)$, da concentração do princípio ativo $(0,2 \%, 0,5 \%$ e $1,0 \%$ ) e a incorporação de um promotor de absorção (Polissorbato 80 ) na penetração do fármaco.

\section{MATERIAIS E MÉTODOS}

\section{Materiais}

O lapachol foi obtido do Instituto de Antibióticos da Universidade Federal de Pernambuco - UFPE. Os reagentes empregados foram álcool etílico p.a., glicerina p.a., acetona p.a., isopropanol p.a. e DMSO p.a., obtidos da Merck ${ }^{\circledR}$. A matéria-prima Carbopol ${ }^{\circledR}$ dos diversos tipos, a trietanolamina e o Polissorbato 80 foram obtidos da GALENA. As membranas artificiais utilizadas nos ensai- os de difusão in vitro foram de natureza celulósica com poros de $0,44 \mathrm{~mm}$ da Millipore ${ }^{\grave{ }}$. Para o ensaio de permeação in vitro utilizando pele animal, foram utilizadas amostras de pele de rato do tipo Wistar com peso entre 280 e 320 g, idade entre 3,0 e 3,5 meses, todos do sexo masculino, previamente preparados para o experimento. Para doseamento foi utilizado cromatógrafo a líquido de alta eficiência HP-Série 1100 (Hewlet Packard), munido de degaseificador, bomba quaternária, injetor manual com loop de $20 \mu \mathrm{L}$, coluna cromatográfica Lichrosorb RP-18 250x4 mm (Merck), detector UV e integrador HP 3395.

\section{Estudo de Solubilidade}

Excesso de lapachol foi adicionado ao veículo teste e foram agitados por 48 horas. A suspensão foi filtrada para obter solução límpida. Os solventes utilizados neste estudo foram acetona, etanol, isopropanol, DMSO, água, mistura etanol:glicerina (50:50) e (70:30). A concentração foi medida utilizando cromatografia a líquido de alta eficiência (CLAE), utilizando coluna Lichrosorb RP-18 250x4 mm e fase móvel constituída por metanol:solução aquosa de ácido acético a 5\% (80:20), detecção em UV a $278 \mathrm{~nm}$ (Fonseca et al., 2003).

\section{Desenvolvimento das formas geleificadas}

Partiu-se da fomulação desenvolvida por Santos et al. (1991), na qual se empregou lapachol veiculado em géis de Carbopol ${ }^{\circledR}$ 934, selecionando como referência aquela que apresentou maior grau de cedência do fármaco. Com base nestes dados e nas características do lapachol, efetuou-se total de 27 formulações utilizando 3 tipos de resinas de $\mathrm{Carbopol}^{\circledR}$, variadas concentrações de lapachol $(0,2 \%, 0,5 \%$ e $1,0 \%)$ e 3 faixas de $\mathrm{pH}$ das formulações $(5$, 7 e 8), como apresentado na Tabela I, fazendo-se variar um parâmetro de cada vêz. Os três tipos de resinas empregadas foram: Carbopol $^{\circledR}$ 941, que apresenta boa estabilida-

TABELA I - Composição das 27 formulações, variando os 3 tipos de Carbopol $^{\circledR}(941,934 \mathrm{P}$ e 940$)$, as concentrações de lapachol $(0,2 \%, 0,5 \%$ e $1,0 \%)$ e o $\mathrm{pH}(5,7$ e 8$)$

\begin{tabular}{ll}
\hline Composição & Quantidades (\% p/p) \\
\hline Carbopol $^{\circledR}$ 934P, 941 ou 940 & 0,50 \\
Glicerina/etanol (30:70) & 40 \\
Trietanolamina q.s.p. & pH 5,0; 7,0 ou 8,0 \\
Lapachol & 0,$2 ; 05$ ou 1,0 \\
Água destilada q.s.p. & 100 \\
\hline
\end{tabular}


de em formulações tópicas inclusive as que apresentam substâncias iônicas, Carbopol ${ }^{\circledR}$ 934P, considerado excelente para uso em transdérmicos e tópicos, e Carbopol ${ }^{\circledR}$ 940, que produz géis hidroalcoólicos com ótima claridade (Goodrich, 1997).

\section{Estudos de permeação in vitro}

O estudo foi realizado utilizando seis células de Franz interligadas a um banho termostatizado, estabilizado a $37^{\circ} \mathrm{C}$ e dispostas nos respectivos pontos de uma placa magnética, promovendo agitação constante do meio receptor. $\mathrm{O}$ volume e a área difusional do compartimento doador correspondiam a aproximadamente $1,5 \mathrm{~mL}$ e $1,15 \mathrm{~cm}^{2}$, respectivamente, e o volume do compartimento receptor correspondia a aproximadamente $5,5 \mathrm{~mL}$. Quantidade em torno de $150 \mathrm{mg}$ do gel foi colocada no compartimento doador e o meio receptor utilizado foi o tampão de fosfato $\mathrm{pH} 7,0$. Em intervalos de tempos prédeterminados, coletou-se todo o líquido receptor, reabastecendo o volume total retirado imediatamente com o próprio líquido receptor na mesma temperatura. No estudo in vitro, membranas sintéticas foram utilizadas, sofrendo hidratação em água destilada por 24 horas antes da montagem nas células de difusão. Para o estudo de permeação utilizando pele animal, ratos albinos adultos, tipo Wistar, foram sacrificados através de exposição ao éter (Crevoisier et al., 1974). A pele fresca foi removida por excisões da região abdominal e dispostas nas células de difusão tipo Franz com a derme em contato com o compartimento receptor (Franz, 1975). O lapachol foi analisado por espectrofotometria. Todas as formulações estudadas foram testadas por este método, para posteriormente servir como parâmetro para definição da melhor preparação.

\section{Análise Estatística}

Para análise dos dados foi utilizados a Análise de variância ( ANOVA).

\section{RESULTADOS E DISCUSSÃO}

A solubilidade do lapachol nos diferentes solventes analisados encontra-se descrita na Tabela II.

A partir destes dados e dos trabalhos anteriormente descritos (Santos et al., 1991), escolheu-se o sistema solvente etanol/glicerina e passou-se a preparar formulações com variadas proporções deste sistema (100\% glicerina, $70 \%$ glicerina: $30 \%$ etanol, $70 \%$ etanol: $30 \%$ glicerina e 50\% etanol: $50 \%$ glicerina). Assim, realizouse estudo preliminar de permeação in vitro utilizando es-
TABELA II - Solubilidade do lapachol em diversos solventes determinados a temperatura ambiente

\begin{tabular}{ll}
\hline Solventes & Solubilidade $(\mathbf{m g} / \mathbf{m L})$ \\
\hline Acetona & 13,88 \\
Etanol & 07,80 \\
Isopropanol & 22,81 \\
DMSO & $>100,00$ \\
Água & $<0,0087$ \\
Etanol/glicerina $(50 / 50)$ & 03,58 \\
Etanol/glicerina $(70 / 30)$ & 05,00 \\
\hline
\end{tabular}

tas proporções como sistema solvente do lapachol. Observou-se maior difusão das formulações com a proporção etanol 70\%: glicerina $30 \%$, sendo estas concentrações utilizadas na preparação dos géis das etapas seguintes (dados não publicados).

Dentre os vários fatores que podem influenciar a penetração cutânea dos fármacos, o pH do veículo, a solubilidade no veículo e a viscosidade do gel são três fatores importantes a considerar. $\mathrm{O} \mathrm{pH}$ exerce sua ação promovendo a presença de formas ionizadas e moleculares do fármaco e estas deveriam mostrar comportamento de penetração diferentes (Kushla et al., 1991). O emprego de três faixas distintas de $\mathrm{pH}(5,7$ e 8$)$ mostrou ser um parâmetro significativo ao se avaliar os perfis cinéticos difusionais de lapachol a partir dos géis (ANOVA, $\mathrm{p}<0,05)$. Os melhores perfis difusionais, considerando apenas o parâmetro $\mathrm{pH}$, foram aqueles observados nas formulações com pH 8 utilizando Carbopol ${ }^{\circledR}$ 934P ( Figura 1), ocasionado talvez pelo fato do lapachol ser um ácido fraco e ter sua solubilidade aumentada neste $\mathrm{pH}$.

Como o aumento da concentração do fármaco na formulação eleva a atividade termodinâmica do sistema, aumentando conseqüentemente o fluxo, foi realizada mudança na concentração inicial do fármaco variando até concentrações supersaturadas com o intuito de promover a permeação. Assim, observou-se aumento proporcional na cedência global do fármaco com a modificação na concentração de 0,2 para $0,5 \%$. Todavia, quando esta última dose foi aumentada em $100 \%$, passando de 0,5 para $1,0 \%$ de princípio ativo, não se verificou uma duplicação na liberação do lapachol para todos os casos. Isto pode ser explicado devido, entre outros, à saturação deste no veículo. Fato observado principalmente devido à presença de cristais de lapachol no veículo ( Figuras 1 e 2).

A atuação do tipo de resina de Carbopol ${ }^{\circledR}$ na permeação in vitro do lapachol a partir dos géis estudados foi avaliada e pode-se constatar que os perfis cinéticos dos 


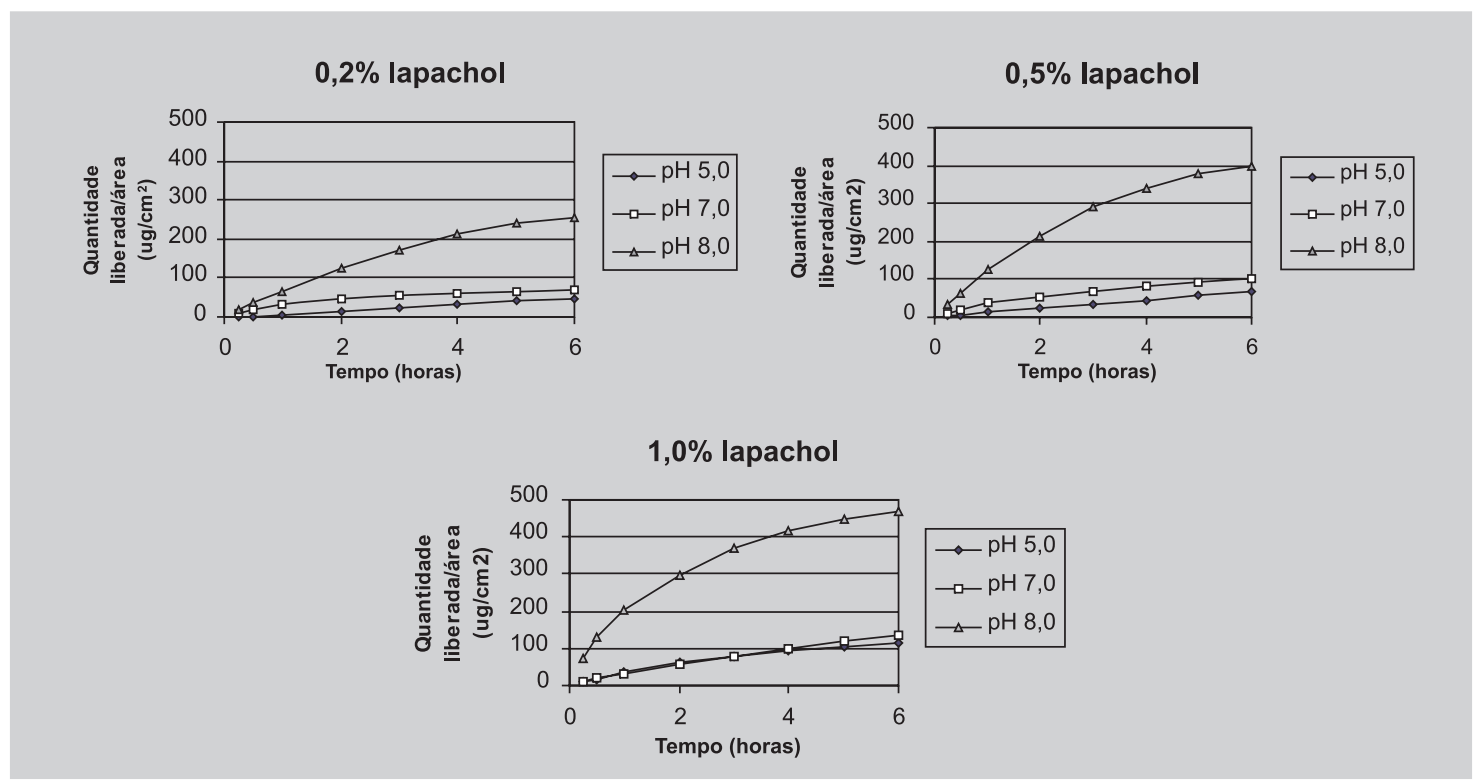

FIGURA 1 - Permeação in vitro de lapachol $\left(\mu \mathrm{g} / \mathrm{cm}^{2}\right)$ a partir de géis de Carbopol ${ }^{\circledR} 934 \mathrm{P}$ em função do $\mathrm{pH}$, nas concentrações $0,2 \%, 0,5 \%$ e $1,0 \%$ de lapachol.

géis contendo 0,2 e 1,0\% de lapachol indicaram diferença significativa entre o uso dos polímeros estudados. Destes, os melhores valores difusionais foram observados com o emprego de Carbopol ${ }^{\circledR}$ 934P e os menores foram caracterizados pelo uso do Carbopol ${ }^{\circledR} 941$ como demonstrado na também na Figura 2. Nos géis a 0,5\% de lapachol, não houve influência significativa com a variação do tipo de Carbopol $^{\text {Ò }}$.

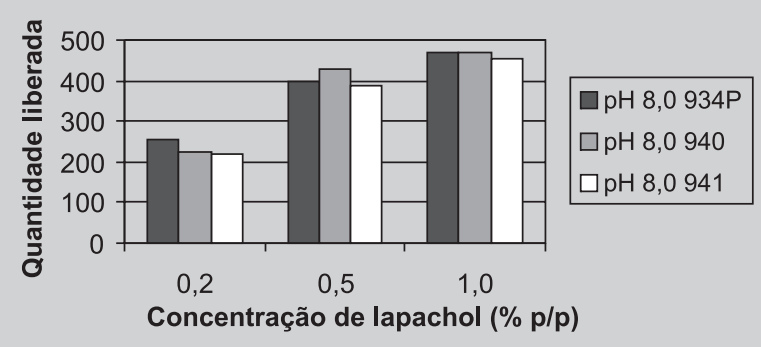

FIGURA 2 - Quantidade total liberada após 6 horas de cinética in vitro de lapachol $(\mu \mathrm{g})$ a partir de géis de carbopol ${ }^{\circledR}$ 934P, 940 e 941 em pH 8,0, nas concentrações $0,2 \%, 0,5 \%$ e $1,0 \%$ do lapachol.

Foram selecionados os géis de Carbopol ${ }^{\circledR} 934 \mathrm{P}$ e 941, a pH 8 , nas concentrações $0,2 \%, 0,5 \%$ e $1,0 \%$ de lapachol, com e sem a incorporação do promotor de absorção Tween ${ }^{\circledR} 80$ a $0,025 \%$ para estudo de permeação utilizando pele animal. Estes dois polímeros foram selecionados por apresentarem respectivamente as preparações onde ocorrem maiores e as menores taxas de liberação in vitro do lapachol nas condições experimentais anteriormente descritas. Os tensoativos têm sido empregados como promotores de penetração para vários fármacos atuando por dois mecanismos diferentes: interações e ligações com filamentos de queratina, resultando em desorganização dos corneócitos e fluidização e conseqüente solubilização do estrato córneo. O Polissorbato 80 age pelos dois mecanismos, pois contém em sua estrutura o óxido de etileno e uma longa cadeia hidrocarbonada, que confere características hidrófilas e lipófilas à molécula (Shokri et al., 2001). A presença do tensoativo teve influência considerável sobre o grau de cedência do lapachol ( $p<0,05$, ANOVA e teste t pareado) e o aumento na concentração de lapachol foi significativo na liberação do princípio ativo, no entanto não manifestou perfil difusional diretamente proporcional ao seu crescimento (Figura 3). A incorporação do Polissorbato 80 foi significativa nas preparações a $0,2 \%$ e $0,5 \%$ de lapachol, como demonstrado pelo valores de fluxo na Tabela III, em que ocorreu aumento do fluxo com a incorporação do Polissorbato 80 nestas formulações. Não houve diferença entre o uso dos polímeros de Carbopol ${ }^{\circledR}$ (934P e 941), no entanto, ocorreu distinção somente nos géis a $1,0 \%$, no qual os géis com Carbopol ${ }^{\circledR} 934 \mathrm{P}$ apresentaram melhores perfis e fluxo bastante superior aos géis com Carbopol $^{\circledR}$ 941(teste t pareado, $\mathrm{p}<0,05$ ).

Assim pode-se concluir que o estudo de permeação in vitro do lapachol sobre Células de Franz mostrou que o 
princípio ativo apresenta boa difusibilidade através de membrana artificial e pele animal, cujos melhores perfis foram observados com os géis de Carbopol ${ }^{\circledR} 934 \mathrm{P}$ a pH 8 , com $0,5 \%$ e $1,0 \%$ de lapachol e o percentual de liberação das preparações foram bem maiores que os relatados em trabalhos publicados anteriormente. O principal fator incidente sobre a liberação do lapachol foi o $\mathrm{pH}$ e embora os outros tenham apresentado algumas alterações significativas nos perfis difusionais o gel de $\mathrm{Carbopol}^{\mathrm{O}}$ 934P com pH 8 e $0,5 \%$ de lapachol parece ser a melhor opção entre as preparações estudadas. Atualmente, os primeiros ensaios farmacológicos in vivo com animais corroboraram estes resultados, cujo trabalho será apresentado posteriormente.

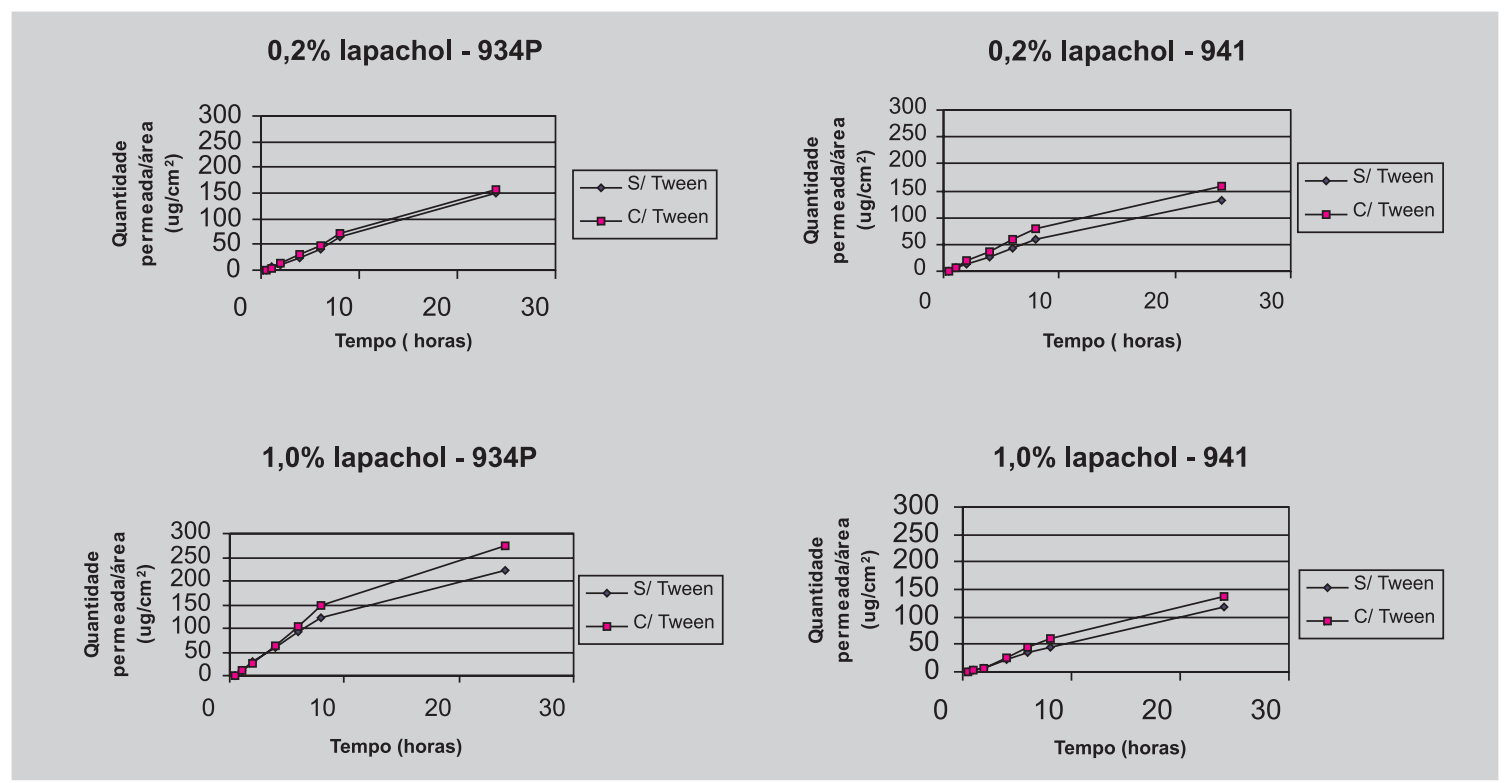

FIGURA 3 - Permeação in vitro de lapachol $\left(\mu \mathrm{g} / \mathrm{cm}^{2}\right)$ a partir de géis de Carbopol ${ }^{\circledR} 934 \mathrm{P}$ e 941 nas concentrações $0,2 \%$, $0,5 \%$ e $1,0 \%$ de lapachol a pH 8,0 em função da presença de Tween ${ }^{\circledR} 80(0,025 \%)$.

TABELA III - Fluxo de liberação do lapachol das diferentes formulações utilizadas nos ensaios in vitro utilizando pele animal

\begin{tabular}{|c|c|c|c|}
\hline & \multicolumn{2}{|c|}{ Parâmetros modificados } & \multirow[t]{2}{*}{ Fluxo* $\left(\mathrm{mg} / \mathrm{cm}^{2} /\right.$ hora $)$} \\
\hline & lapachol (\%) & Tween ${ }^{\circledR} 80$ & \\
\hline \multirow{6}{*}{ Carbopol 934p } & 0,2 & com & 6,66 \\
\hline & & sem & 6,32 \\
\hline & 0,5 & com & 9,15 \\
\hline & & sem & 6,27 \\
\hline & 1,0 & com & 19,71 \\
\hline & & sem & 16,13 \\
\hline \multirow{6}{*}{ Carbopol 941} & 0,2 & com & 10,25 \\
\hline & & sem & 5,44 \\
\hline & 0,5 & com & 11,11 \\
\hline & & sem & 6,78 \\
\hline & 1,0 & com & 5,81 \\
\hline & & sem & 5,05 \\
\hline
\end{tabular}

* Calculado na porção linear da curva ("steady state”) 


\section{AGRADECIMENTOS}

Os autores agradecem ao CNPq e à CAPES pelo suporte financeiro, assim como ao Laboratório Farmacêutico do Estado de Pernambuco (LAFEPE) e ao Instituto de Antibióticos da UFPE, pelo fornecimento da matéria-prima lapachol.

\section{ABSTRACT \\ Preliminary development of lapachol gel: in vitro permeation study}

The scope of this work was to develop two gel formulations containing lapachol, substance with known anti-inflammatory activity. In order to achieve a more effective topical delivery, the effects of vehicles and enhancers were evaluated. The influence of the Carbopol ${ }^{\circ}$ resin (934P, 940 and 941), the $p H$ of the formulation (5, 7 and 8$)$, the concentration of the active $(0.2 \%, 0.5 \%$ and $1.0 \%)$ and the incorporation of Tween ${ }^{\circledR} 80$ were investigated. A series in vitro permeation studies were conduct in classical Franz-type diffusion cells using Durapore ${ }^{\circledR}$ synthetic membranes and Wistar mouse skins as barriers. Through the careful analyse of the data obtained, we could observe that the addition of Tween ${ }^{\circledR} 80$ leads to a significant increase in the in vitro diffusion of the active, except for the formulations containing Carbopol $^{\circledR}$ 934P and $0.2 \%$ of lapachol. The formulations assayed presented best in vitro diffusion rates of lapachol at $\mathrm{pH} 8$ when $0.5 \%$ or $1.0 \%$ of the active was added. However, the preparations containing $1.0 \%$ of drug presented little insoluble crystals of lapachol.

UNITERMS: Lapachol. Gels. In vitro diffusion.

\section{REFERÊNCIAS BIBLIOGRÁFICAS}

ALMEIDA, E. R., SANTOS, E. R., SILVA, A. A. F., CORREIA, C. A. Antiiflamatory action of Lapachol. $J$. Ethnopharmacol., v. 29, p. 239-241, 1990.

ALMEIDA, M. E.; BRANDÃO, M. A.; GUERRA, M. O.; PETERS, V. M. Avaliação preliminar do efeito interceptivo do lapachol em ratas Wistar. Bol. Centro Biol. Reprod., v. 18, p. 37-48, 1999.

BARRY, B. W. Mode of action of penetration enhancers in human skin. J. Controlled Release, v.6, p. 85-97, 1987.
CHIEN, Y. W. Novel drug delivery systems. New York: Marcel Dekker, 1992, v. 50, p. 797.

CORREIA, L. C. A.; SILVA, A. A. F. Primeiros ensaios utilizando o Lapachol em pacientes portadores de bursite na fase aguda. In: SIMPÓSIO DE PLANTAS MEDICINAIS DO BRASIL, 10., São Paulo, 1988. Anais. Local de publicação: Editora, ano de publicação. Páginas?.

CORREIA, L. C. A.; SILVA, A. A. F. Primeiros informes na utilização do Lapachol em pacientes portadores de Tendinite. In: SIMPÓSIO DE PLANTAS MEDICINAIS DO BRASIL, 10., São Paulo, 1988. , Anais. . Local de publicação: Editora, ano de publicação. Páginas?.

CORREIA, L. C. A.; SILVA, A. A. F. Primeiras observações com o emprego do lapachol em gotas, em pacientes portadoras de otites agudas e crônicas. In: SIMPÓSIO DE PLANTAS MEDICINAIS DO BRASIL, 10., São Paulo, 1988. Anais. Local de publicação: Editora, ano de publicação. Páginas?.

CORREIA, L. C. A.; SILVA, A. A. F. Primeiras observações utilizando o lapachol em gotas em pacientes portadores de sinusites agudas e crônicas. In: SIMPÓSIO DE PLANTAS MEDICINAIS DO BRASIL, 10., São Paulo, 1988. Anais. . Local de publicação: Editora, ano de publicação. Páginas?.

CREVOISIER, C.; BURI, P.; BOUCHERAT, J. Étude du transport de trois flavonoïdes à travers des membranes artifialles et biologiques. Pharm. Acta Helv., v.49, n. 3/4, Páginas?, 1973.

FRANZ, T.J. Percutaneus absorption on relevance of in vitro data. J. Invest. Dermatol., v. 64, p. 190, 1975.

FONSECA,S.G.C., SILVA, L.B.L., CASTRO, R.F., SANTANA, D.P. Validação de Metodologia analítica para doseamento de soluções de Lapachol por CLAE. Química Nova, v. 27, n. 1, p. 157-159, 2004.

GONÇALVES DE LIMA, O., d'ALBUQUERQUE, I. L., MACHADO, M. P. Uma nova substância isolada do Pau d'arco, Tabebuia sp. Anais Soc. Biol. Pernambuco, v. 14, n.1/2: p.136-140, 1956.

GUY, R. H.; HADGRAFT, J. Transdermal drug delivery: the ground rules are emerging. Pharm. Int., v. 6, p.112-116, 1985. 
GWAK, H. S.; CHUN, I. K. Effects of vehicles and penetration enhancers on the in vitro percutaneous absorption of tenoxican through hairless mouse skin. Int. J. Pharm., v.236, p. 57-64, 2002.

KUSHLA, G. P.; ZATZ, J. L. Influence of pH on lidocaine penetration through human and hairless mouse skin in vitro. Int. J. Pharm., v. 71, p. 167-173, 1991.

LUI, C. Y.; AYENI, A. A.; GYLLENHAAL, C.; GROVES, M. J. Some formulation properties of Lapachol, a potential oncolytic agent of natural origin. Drug Dev. Ind. Pharm., v. 11, n. 9/10, p. 63-1779, 1985.

MOSER, K.; KRIWET, K.; NAIK, A.; KALIA, Y.N.; GUY, R.H. Passive skin penetration enhancement and its quantification in vitro. Eur. J. Pharm. Biopharm., v. 52, n.2, p. 103-112, 2001.

PHARMACEUTICAL POLYMERS. Bulletin 14: Formulation topical properties. jan. 2002. p. 1-16. Disponível em http://www.pharma.noveoninc.com/ literature/billetin/epb14.pdf. Acesso em: 30 jan. 2003.

SANTOS, E.R.; PRISTA, L.V.N.; LOBO, J.M.S.; SANTOS, D.G. Estudos de difusão cutânea do Lapachol. I Ensaios "in vitro". Rev. Port. Farm., v. 41, n. 3, p. 15-19, 1991.

SANTUS, G.C.; BAKER, R.W. Transdermal enhancer patent literature. J. Controlled Release, v. 25, p. 1-20, 1993.

SHOKRI, J.; NOKHODCHI, A.; DASHBOLAGHI, A.; HASSAN-ZADEH, D.; GHAFOURIAN, T.; JALALI, M. B. The effect of surfactants on the skin penetration of diazepan. Int. J. Pharm., v. 228, p. 99-107, 2001.
SWARBRICK, J.; LEE, G.; BROM, J.; GENSMANTEL, N.P. Drug permeation through human skin II: permeability of ionizable compounds. J. Pharm. Sci., v. 73, n. 10, p. 1352-1355, 1984.

WANICK, M. C.; BANDEIRA, J. A. ; FERNANDES, R. V. Ação antiinflamatória e cicatrizante do extrato hidroalcoólico do Líber do Pau d'arco Roxo (Tabebuia avellanedae), em pacientes portadores de Cervicites e Cérvico-vaginites. Rev. Inst. Antibióticos, Recife, v.10, n. 1/2: p.41-46, 1970.

YAMANE, M. A.; WILLIAMS, A. C.; BARRY, B. W. Effects of terpenes and oleic acid as skin penetration enhancers towards 5-fluorouracil as assessed with time; permeation, partitioning and differential scanning calorimetry. Int. J. Pharm., v. 116, p. 237-251, 1995.

YOKOMIZO, Y. Effects of phosphatidylcholine on the percutaneous penetration of drugs the dorsal skin of guinea pigs in vitro; and analysis of the molecular mechanism, using attenuated total reflectance-fourier transform infrared (ATF-FTIR) spectroscopy. J. Controlled Release, v.42, p. 249-262, 1996.

ZATZ, J.L. Fundamental of transdermal controlled drug administration: physicochemical considerations. Drug Dev. Ind. Pharm., v.9, n. 4, p. 561-577,1983.

Recebido para publicação em 18 de fevereiro de 2003. 